Tropical Journal of Pharmaceutical Research February 2013; 12 (1): 27-32

ISSN: $1596-5996$ (print); 1596-9827 (electronic)

(c) Pharmacotherapy Group, Faculty of Pharmacy, University of Benin, Benin City, 300001 Nigeria.

All rights reserved.

Available online at http://www.tjpr.org

Original Research Article

http://dx.doi.org/10.4314/tjpr.v12i1.5

\title{
Effect of Permeation Enhancers on the Release Behavior and Permeation Kinetics of Novel Tramadol Lotions
}

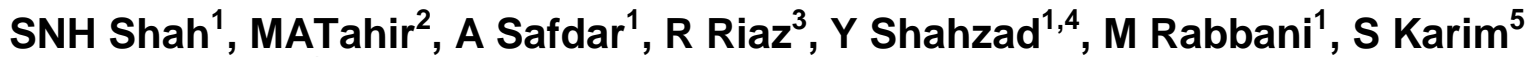 \\ and G Murtaza ${ }^{6^{*}}$ \\ ${ }^{1}$ Faculty of Pharmacy, Bahauddin Zakariya University, Multan, Pakistan. ${ }^{2}$ Department of Pharmacy, University of Lahore, \\ Lahore, Pakistan. ${ }^{3}$ SNS Pharmaceutical Research Laboratory, Multan, Pakistan. ${ }^{4}$ Division of Pharmacy and Pharmaceutical \\ Sciences, School of Applied Sciences, University of Huddersfield HD1 3DH, UK. ${ }^{5}$ College of Pharmacy, University of the \\ Punjab, Lahore, Pakistan. ${ }^{6}$ Department of Pharmaceutical Sciences, COMSATS Institute of Information Technology, \\ Abbottabad-22060, Pakistan.
}

*For correspondence: E-mail: gmdogar356@gmail.com; Tel: 0092-314-2082826; Fax: 0092-922-383441

Received: 24 March 20121

Revised accepted: 3 December 2012

\begin{abstract}
Purpose: The aim of this research work was to formulate, characterize and evaluate the in vitro permeation behavior of tramadol lotion containing propylene glycol (PG) and polyethylene glycol (PEG) as permeation enhancers.

Methods: The permeation experiments were conducted in vitro using full thickness rabbit skin in Franz diffusion cells. The donor compartment was filled with PBS (phosphate buffered saline) at pH 7.4 \pm 0.1 . The receptor phase was continuously stirred PBS $(\mathrm{pH} 7.4)$ at $37{ }^{\circ} \mathrm{C} \pm 0.5$. The amount of tramadol permeated into the receptor phase was determined spectrophotometrically at $271 \mathrm{~nm}$. Various permeation parameters such as permeation coefficient (Kp), diffusion coefficient $(D)$, flux $(J)$, input rate, and enhancement ratio were obtained using Fick's diffusion laws.

Results: Permeation increased with increase in the concentrations of both enhancers tested. Maximum cumulative amount permeated for control lotion $\left(L_{c}\right)$ was $357 \mu \mathrm{g} / \mathrm{cm}^{2} / \mathrm{min}$ with input rate $0.574 \mu \mathrm{g} / \mathrm{min}$ and lag time (t tag) of $34.93 \mathrm{~min}$, while for the optimum test lotion ( $L_{4}$, containing $8 \%$ PG/PEG in ratio of $1: 1 \mathrm{v} / \mathrm{v})$, it was $926 \mu \mathrm{g} / \mathrm{cm}^{2} / \mathrm{min}, 1.482 \mu \mathrm{g} / \mathrm{min}$ and $58.36 \mathrm{~min}$, respectively. The significantly $(p<0.05)$ higher permeability shown by the test lotion $L_{4}$ can be attributed, in part, to the interaction of $P G$ with intercellular lipids leading to the disruption of their organization and increasing their fluidity, and also partly as a result of solubilization of lipid bilayers by PEG.

Conclusion: A binary system of PG and PEG in lotion can be successfully utilized for the permeation enhancement of tramadol.
\end{abstract}

Keyword: Tramadol, Transdermal delivery, Permeation, Propylene glycol, Polyethylene glycol, Rabbit skin.

Tropical Journal of Pharmaceutical Research is indexed by Science Citation Index (SciSearch), Scopus, International Pharmaceutical Abstract, Chemical Abstracts, Embase, Index Copernicus, EBSCO, African Index Medicus, JournalSeek, Journal Citation Reports/Science Edition, Directory of Open Access Journals (DOAJ), African Journal Online, Bioline International, Open-J-Gate and Pharmacy Abstracts

\section{INTRODUCTION}

In a broad sense, the term TDDS (transdermal drug delivery system) includes all topically administered drug formulations intended to deliver the active ingredient into general circulation [1]. Ideally, the entire drug should penetrate through the skin to the underlying blood supply without any accumulation in the layers of the skin for successful transdermal delivery which often involves a demonstration of clinical safety and effectiveness.

Although TDDS was introduced more than 200 years ago [2], it is only recently that the method 
appears to have reached a practical stage [3]. A closely related term is percutaneous delivery, which is the transport of drugs into target tissues with the aim to avoid systemic effects. The concept of percutaneous absorption of drugs was given by Stoughton in 1965 [4). TDDS provides various merits over conventional drug delivery systems such as oral and parenteral delivery, including avoidance of hepatic first pass metabolism, reduction of pain, and possible sustained release of drugs [5-7].

Chemical enhancers are substances which momentarily diminish skin obstacle and accelerate drug absorption. Enhancers include essential oils, terpenes, terpenoids, azone, pyrrolidones, fatty acids, sulphoxides, oxazolidinones and urea. Propylene glycol and polyethylene glycol can easily penetrate the skin and has assessed as a skin penetration enhancer in several in vitro studies [8].

Tramadol $\mathrm{HCl}$ (TRA) is a centrally acting opioid synthetic analgesic which acts through selective binding to the $\mu$-opioid receptor as well as weak inhibition of norepinephrine and serotonin uptake. It is employed in severe acute or chronic pains. TRA is a basic drug with $\mathrm{pKa}=9.3[9,10]$. To the best of our knowledge, no study has addressed in detail the formulation of tramadol as a lotion. The aim of this work, therefore, was to formulate, characterize and evaluate the in vitro permeation behavior of tramadol lotion containing propylene glycol (PG) and polyethylene glycol (PEG) as permeation enhancers.

\section{EXPERIMENTAL}

\section{Chemicals}

Tramadol hydrochloride (purity $99.7 \%$, TRA) was a gift by Ali Gohar Pharmaceuticals, Karachi, Pakistan. Propylene glycol (PG), isopropyl alcohol (IPA) and sodium chloride $(\mathrm{NaCl})$ were purchased from Merck, Germany. Polyethylene glycol (PEG 1000), potassium dihydrogen phosphate and disodium hydrogen phosphate $\left(\mathrm{Na}_{2} \mathrm{HPO}_{4} \cdot 12 \mathrm{H}_{2} \mathrm{O}\right)$ were procured from Fluka, Germany. Potassium chloride $(\mathrm{KCl}$, Aldrich Chemical, USA), vacuum grease (Dow Corning, USA), carbomer-980 (Merck, Germany), sodium hydroxide (Shama Laboratory Chemical Works, Lahore) were purchased from local suppliers. All the chemicals used were of analytical grade and used without further treatment. Glass double-distilled water was used throughout the study.

\section{Preparation of hydro-alcoholic lotions}

Hydro-alcoholic lotions $\left(L_{1}-L_{5}, 100 \mathrm{ml}\right.$ each) of TRA having varying concentrations $(2,4,6,8$ and $10 \%$ ) of permeation enhancers (PG and $P E G$ in a ratio of $1: 1 \mathrm{v} / \mathrm{v}$ ) were prepared in a 100 $\mathrm{ml}$ volumetric flask. To prepare the lotions, TRA (50 mg) was dissolved in $10 \mathrm{ml}$ of isopropyl alcohol in a $100 \mathrm{ml}$ volumetric flask followed by the addition of carbomer-980 (1.5 mg) with continuous shaking. PG, PEG, and phosphate buffer $(0.1 \mathrm{ml})$ were added and the volume made up to $100 \mathrm{ml}$ with distilled water. Control formulation (LC) which contained the same ingredients in the same amounts, except an enhancer, was also made.

\section{In vitro characterization studies}

Each TRA-containing lotion was tested to assess its physical properties including $\mathrm{pH}$, viscosity, spreadability, homogenity and drug solubility. Each of these analyses was conducted in triplicate $(n=3)$.

The $\mathrm{pH}$ of the lotions was tested using a digital pH meter (Mettler \& Toledo, Giessen, Germany). The viscosity was determined using a Brookfield viscometer (Model RVTDV II, Stoughton, USA) at room temperature $\left(25 \pm 2{ }^{\circ} \mathrm{C}\right)$. A C-50 spindle was used with a stirring speed of $220 \mathrm{rpm}$. The gap value was fixed at $0.3 \mathrm{~mm}$.

Lotion spreadability was tested by the wooden block and glass slide method as presented previously [11]. Briefly, $5 \mathrm{~mL}$ of the lotion was adjoined to a dedicated pan and the time taken for a movable upper slide to detach entirely from the fixed slides was observed. Spreadability (S) was evaluated asin $\mathrm{Eq} 1$.

$S=M \cdot L / t$

where $\mathrm{M}=$ weight/volume tide to upper slide, $\mathrm{L}=$ length of glass slide and $t=$ time taken to separate the slide completely from each other.

Visual examination was used to evaluate the homogeneity of each lotion. To assess aggregation, the appearance of the lotions was observed [12].

Each TRA-containing lotion was tested for drug content. The lotion $(5 \mathrm{~mL})$ was dissolved in ethanol $(5 \mathrm{~mL})$ and PBS $(\mathrm{pH} \mathrm{7.4)}$ added to make up the final volume to $100 \mathrm{~mL}$. The mixture was vigorously mixed for $2 \mathrm{~h}$ on a mechanical shaker, filtered and the supernatant layer then analyzed spectrophotometrically for TRA at $271 \mathrm{~nm}$ using UV/Vis spectrophotometer (model 1601, Shmadzu, Japan) [7]. 


\section{Stability studies}

Accelerated stability studies of the formulated lotions were conducted at a temperature of $40 \pm$ $2 \stackrel{\circ}{ } \mathrm{C}, 75 \% \mathrm{RH}$ for 3 months. Each lotion was tested for alterations in its appearance, $\mathrm{pH}$, viscosity and drug content after $12 \mathrm{~h}, 1$ day, 7 days, 1 month and 3 months. Each of these analyses was conducted in triplicate $(n=3)$.

\section{In vitro permeation studies}

In vitro permeation studies of TRA lotions across rabbit skin were carried out using two-chambered Franz-type diffusion cells (manufactured "in house") [6] having a receptor phase of $\sim 5 \mathrm{ml}$, and a diffusional area of $~ 0.788 \mathrm{~cm}^{2}$.

Following approval (approval No. 342008/BZU.PHM) by the Board of Advance Studies and Research, Faculty of Pharmacy, Bahauddin Zakariya University, Multan, Pakistan, this study was conducted in accordance with the international guidelines for animal use in laboratory experimentation [13]. Adult rabbit skin was used for permeation studies at $37 \pm 0.5^{\circ} \mathrm{C}$. Abdominal full thickness skin of male White New Zealand rabbit ( 3 - $4 \mathrm{~kg}$ weight) was carefully excised after sacrificing the rabbit. Subcutaneous fats and other extraneous tissues adhering to the dermis were completely removed and trimmed with forceps and scissor. The skin was cleaned with phosphate buffered saline (PBS) at $\mathrm{pH} 7.4$ and stored in $500 \mathrm{ml}$ normal saline in a refrigerator $\left(18-20^{\circ} \mathrm{C}\right)[6,7]$.

The skin was used within one week of excision. Sheets of the skin were cut to appropriate sizes $\left(\sim 1 \mathrm{~cm}^{2}\right.$ in diameter) and soaked overnight in the receptor solution (PBS). The membrane was then placed between the two compartments of the diffusion cells with epidermis side facing the donor compartment while the dermal side was bathed with PBS at pH 7.4 (receptor fluid). The donor compartment was filled with PBS at $\mathrm{pH} 7.4$ \pm 0.1 . This $\mathrm{pH}$ is close to that of human skin. The receptor fluid was stirred with a magnetic stirring bar at $500 \mathrm{rpm}$, keeping the temperature at $37 \pm$ $0.5{ }^{\circ} \mathrm{C}$ by means of a water jacket. Care was exercised to remove any bubbles between the underside of the skin and the solution in the receiver compartment. Vacuum grease was used to produce a leak-proof seal between the membrane and the two compartments of the diffusion cell, i.e., donor and receptor.

The receptor and donor compartments were filled with PBS at $\mathrm{pH} 7.4 \pm 0.1$. To remove air bubbles and preclude the development of air pockets in the receptor phase, PBS was degassed in an ultrasonic bath. To avoid evaporation from the compartments, the cell arm and donor compartment were covered with a parafilm.

Constant mixing of the receptor phase was obtained with a magnetic stirrer placed in the receptor compartment. The diffusion cells were placed on a stirring-bed immersed in a water bath at $37 \pm 0.05^{\circ} \mathrm{C}$, to maintain the temperature of membrane surface. After 24 hours, both chambers were cleared of PBS and the receptor compartment was immediately refilled with prethermostated PBS, while the skin remained intact. The donor compartment was charged with $1 \mathrm{ml}$ of the lotion (test formulation). At time intervals of $5,15,30,60,90,120,180,240,360$ and $480 \mathrm{~min}, 0.2 \mathrm{ml}$ sample was drawn, using a micro-pipette, from receptor solution followed by addition of same volume of pre-thermostated receptor solution to maintain sink conditions. The samples were analyzed spectrophotometrically at $271 \mathrm{~nm}$ using UV/Vis spectrophotometer (model 1601, Shmadzu, Japan) to obtain the amount of TRA permeated through rabbit skin after diluting with $1.8 \mathrm{ml}$ PBS. Since skin shows great sampleto-sample permeability variations [12], each of these analyses was conducted in pentaplicate ( $\mathrm{n}$ $=5)$.

To construct a calibration curve, $500 \mathrm{mg}$ of TRA was dissolved in PBS $(10 \mathrm{ml})$ in $100 \mathrm{ml}$ volumetric flask and the final volume made up to $100 \mathrm{ml}$ by adding PBS to prepare stock solution. From this solution, dilutions of $10,20,30,40,50$, 60,70 , and $80 \mu \mathrm{g} / \mathrm{ml}$ were prepared. The resultant dilutions were analyzed spectrophotometrically for UV absorbance' maximum UV absorbance of TRA was found at $271 \mathrm{~nm}[9,10]$. The linear equation of the constructed calibration curve was $y=0.022 x$ 0.021 and correlation coefficient $\left(R^{2}\right)$ of 0.998 .

Steady-state flux was determined from the slope of the linear portion of the cumulative amount of permeation $(\mathrm{Q})$ versus time ( $\mathrm{t}$ ) plot.

The input rate of TRA (Table 1) permeating across rabbit skin was determined as in Eq 2

$$
\text { Input rate }=K_{p} \times C \times A
$$

where, $K_{p}$ is permeability coefficient, $C$ is donor amount $(\mu \mathrm{g})$, i.e., amount of drug in the donor compartment and $\mathrm{A}$ is the Franz cell area of permeation $\left(\sim 0.788 \mathrm{~cm}^{2}\right)$. Enhancement ratio (ER) was calculated by dividing the flux of the test formulation by the flux of control formulation.

\section{Statistical analysis}

The results are expressed as mean \pm standard deviation (SD, $n=5$ ). Statistically significant differences between various permeation data 
were determined using F-test, Fisher's least significant difference (LSD), analysis of variance (ANOVA) and multiple range tests at $95 \%$ confidence level.

\section{RESULTS}

\section{Physicochemical characteristics of the tramadol lotions}

All TRA-containing lotions $\left(L_{1}-L_{5}\right)$ emerged as clear, colorless and homogenous solutions without any aggregates. The $\mathrm{pH}$ of all the lotions was $\sim 7.9$ and there was no significant difference $(p>0.05)$ among all the formulations. There was, however, significant differences in their viscosities $(p<0.05)$, viz, $(54.00 \pm 0.93) \times 10^{-3}$, $(57.00 \pm 0.86) \times 10^{-3},(64.00 \pm 1.12) \times 10^{-3},(71.00$ $\pm 1.33) \times 10^{-3}$ and $(97.00 \pm 1.19) \times 10^{-3} \mathrm{~g} \mathrm{~cm}^{-1} \mathrm{~s}^{-1}$ for $L_{1}, L_{2}, L_{3}, L_{4}$ and $L_{5}$, respectively. Spreadability also varied significantly $(p<0.05)$, being $2.91 \pm 0.11,2.83 \pm 0.08,2.03 \pm 0.02,1.87$ \pm 0.04 and $1.10 \pm 0.03 \mathrm{mg} \mathrm{cm} \mathrm{s}^{-1}$, respectively. It is evident from these values that spreadability of lotion decreased with the increase in PG-PEG content.

Based on visual observation, no formulation showed any alteration in appearance, opaqueness or color at the end of the accelerated stability studies. There was also no significant difference $(p>0.05)$ in $\mathrm{pH}$, viscosity, spreadability, drug content or permeation through rabbit skin at the end of the accelerated stability studies.

\section{In vitro permeation}

The cumulative amount permeated of TRA through rabbit skin using different hydro-alcoholic lotions is presented in Figure 1. The input rate of tramadol is shown in Table 1 . The various permeation parameters calculated for the lotions are shown in Table 2. Drug permeation data (through full thickness rabbit skin) are given in Figure 1. A significant difference between the cumulative amount $\left(\mu \mathrm{g} / \mathrm{cm}^{2}\right)$ of TRA permeated through rabbit skin in the presence of $P G$ and $P E G$ as permeation enhancers was found when F-Test, Fisher's least significant difference (LSD), and multiple range tests were employed, but the multiple range test did not show a significant difference between $L_{4}$ and $L_{5}(p>$ $0.05)$. This is also supported by the calculated enhancement ratio data shown in Table 2.

The data presented here show that PG and PEG have synergistic effects on the delivery of TRA across the skin. The results also indicate that permeation of TRA increased with increase in the concentration of $P G$ and PEG; maximum cumulative amount of TRA permeated through rabbit skin was obtained with $L_{4}$ (Figure 1). $L_{1}, L_{2}$ and $L_{3}$ showed largely the same permeation enhancement effects.

Table 1: Input rate $\left(\mu \mathrm{g} / \mathrm{cm}^{2}\right.$. $\left.\mathrm{min}\right)$ of TRA from hydroalcoholic lotions

\begin{tabular}{cc}
\hline Lotion & Input rate $\left(\boldsymbol{\mu g} / \mathbf{c m}^{\mathbf{2}} \cdot \mathbf{m i n}\right)$ \\
\hline$L_{c}$ & 0.574 \\
$L_{1}$ & 0.645 \\
$L_{2}$ & 0.698 \\
$L_{3}$ & 0.737 \\
$L_{4}$ & 1.482 \\
$L_{5}$ & 1.002 \\
\hline
\end{tabular}

\section{DISCUSSION}

The stratum corneum (SC) of mammalian skin is considered to be a permeation barrier for water and most solutes whereas the intercellular lipid multilayer domains of SC are believed to present a diffusional pathway for most lipophilic solutes. Permeation enhancers ( $P G$ and $P E G$ ) enter the SC and change the solution properties of SC by altering the chemical environment and thus dissolve the barrier capacity of this cutaneous layer [7].

The apparent effects of the enhancers (PG and $P E G)$ used in the present study may be dependent on their concentrations as evident

Table 2: Computed permeation parameters for tramadol lotions

\begin{tabular}{|c|c|c|c|c|c|c|}
\hline \multirow[b]{2}{*}{ 돈 } & \multicolumn{6}{|c|}{ Permeation parameter } \\
\hline & $\begin{array}{l}\text { Lag time } \\
\left(t_{\text {lag }}, \text { min }\right)\end{array}$ & $\begin{array}{l}\text { Diffusion } \\
\text { coefficient } \\
\left(\mathrm{cm}^{2} / \mathrm{min}\right)\end{array}$ & $\begin{array}{c}\text { Permeation } \\
\text { coefficient } \\
(\mathrm{cm} / \mathrm{min})\end{array}$ & 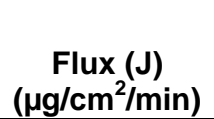 & $\begin{array}{c}\text { Input rate } \\
\left(\mu \mathrm{g} / \mathrm{cm}^{2} . \mathrm{min}\right)\end{array}$ & $\begin{array}{c}\text { Enhancement } \\
\text { ratio }\end{array}$ \\
\hline $\mathrm{L}_{c}$ & 34.94 & 0.045 & 0.001457 & 0.73 & 0.57 & - \\
\hline $\mathrm{L}_{1}$ & 38.43 & 0.049 & 0.001637 & 0.82 & 0.65 & 1.12 \\
\hline $\mathrm{L}_{2}$ & 47.27 & 0.061 & 0.001771 & 0.89 & 0.69 & 1.21 \\
\hline $\mathrm{L}_{3}$ & 73.86 & 0.095 & 0.001871 & 0.94 & 0.74 & 1.28 \\
\hline $\mathrm{L}_{4}$ & 58.37 & 0.075 & 0.003762 & 1.88 & 1.48 & 2.58 \\
\hline $\mathrm{L}_{5}$ & 64.56 & 0.083 & 0.002542 & 1.27 & 1.00 & 1.74 \\
\hline
\end{tabular}


Table 3: Multiple range tests: $95.0 \%$ LSD

\begin{tabular}{cccc}
\hline Formulation & Count & Mean & Homogeneous groups \\
\hline LC $_{1}$ & 10 & 140.742 & $\mathrm{X}$ \\
$\mathrm{L}_{1}$ & 10 & 160.892 & $\mathrm{X}$ \\
$\mathrm{L}_{2}$ & 10 & 181.845 & $\mathrm{X}$ \\
$\mathrm{L}_{3}$ & 10 & 217.081 & $\mathrm{X}$ \\
$\mathrm{L}_{5}$ & 10 & 282.993 & $\mathrm{XX}$ \\
L4 & 10 & 407.094 & $\mathrm{X}$ \\
Multiple range tests & & & \\
\hline Contrast & Sig. & Difference & $\mathbf{+ 1 - \text { Limits }}$ \\
\hline L1 - L2 & & -20.9523 & 167.148 \\
L1 - L3 & & -56.188 & 167.148 \\
L1 - L4 & $*$ & -246.202 & 167.148 \\
L1 - L5 & & -122.101 & 167.148 \\
L1 - LC & & 20.1501 & 167.148 \\
L2 - L3 & & -35.2357 & 167.148 \\
L2 - L4 & $*$ & -225.25 & 167.148 \\
L2 - L5 & & -101.148 & 167.148 \\
L2 - LC & & 41.1024 & 167.148 \\
L3 - L4 & $*$ & -190.014 & 167.148 \\
L3 - L5 & & -65.9126 & 167.148 \\
L3 - LC & & 76.3381 & 167.148 \\
L4 - L5 & & 124.101 & 167.148 \\
L4 - LC & $*$ & 266.352 & 167.148 \\
L5 - LC & & 142.251 & 167.148 \\
\hline
\end{tabular}

* Denotes statistically significant difference.

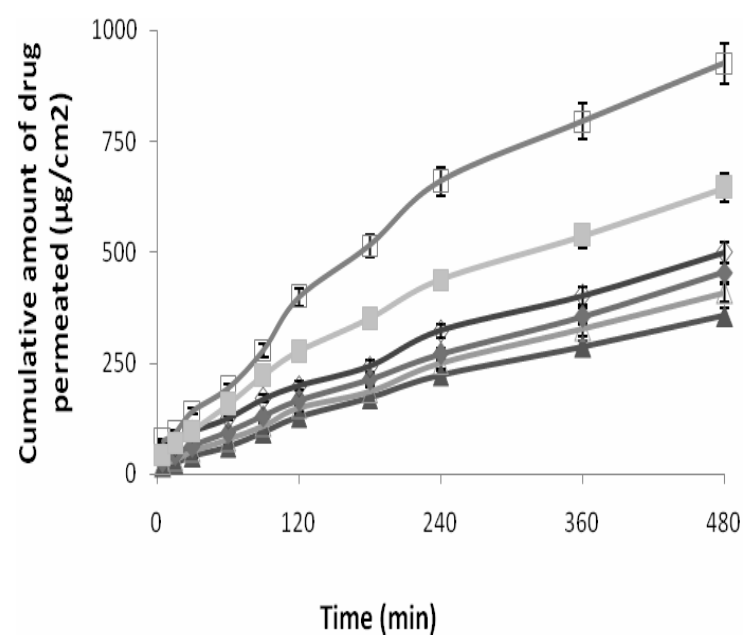

Figure 1: Permeation profile of tramadol from various hydro-alcoholic lotions through rabbit skin; mean \pm SD $(\mathrm{n}=5)(-\boldsymbol{\Delta}-\mathrm{Lc},-\Delta-\mathrm{L} 1,-\bullet-\mathrm{L} 2,-\diamond-\mathrm{L} 3,-\square-\mathrm{L} 4,-\mathbf{m}-\mathrm{L}$ )

from results obtained. Permeation rate through rabbit skin followed Fick's diffusion law and was mainly affected by the amount of PG and PEG1000 [14]. The increase in permeation with increase in enhancer content (except for $L_{5}$ ) is expected based on the effect of the effect of enhancers on the skin which was mentioned above. The different behavior of $L_{5}$ may be due to very high levels of enhancers leading possibly to retention of drug in the skin [15] as indicated in Table 2.

PG also increases drug partitioning and drug permeation [16] and in combination with PEG and other enhancers, PG may increase drug flux possibly due to occupation of its hydrogen bonding sites as well as salvation of the keratin of stratum corneum. It has been suggested that the mechanism of skin permeation enhancement by $P G$ occurs through the extraction of lipids from the SC layers $[6,7,16]$.

PEG due to its solublizing properties is considered a good skin permeation enhancer, and when other lipophilic and hydrophilic surfactants are incorporated with it in formulations, enhances solubility and reduces hepatic metabolism by forming chylomicrons that uncrease lymphatic delivery, resulting in increased bioavailability [17]. This is buttressed by drug flux value of $1.271 \mu \mathrm{g} / \mathrm{cm}^{2} / \mathrm{min}$ for $L_{5}$ which is lower than that of $L_{4}$ due to greater 
solubliztion of the drug in the presence of high levels of PEG [18].

The increased permeability shown by $L_{4}$ can be attributed, in part, to the interaction of PG with intercellular lipids, leading to disruption of their structural organization and increase in their fluidity and partial solubilization of the lipiophilic matrix by PEG. While $K$ values are in order of $L_{4}$ $>L_{1}>L_{5}>L_{2}>L_{3}$ and $D$ values of the lotion are in order of $L_{3}>L_{5}>L_{4}>L_{2}>L_{1}$, thus indicating that increase in PG and PEG-1000 levels also increased the diffusivity of TRA across skin layers.

\section{CONCLUSION}

The data presented in this work suggest that formulation of an effective TDDS for the delivery of tramadol hydrochloride (TRA) is feasible. Improvement in the solubility and diffusivity of TRA is necessary to realize clinically effective transdermal delivery of the drug. Among the various combinations of $P G$ and $P E G$ examined in this study, formulation $\mathrm{L}_{4}$ (containing $8 \%$ PG/PEG 1000 in a 1:1 ratio) yielded the most promising TDDS. Further work would, however, be required to achieve clinical levels in experimental animals and humans.

\section{REFERENCES}

1. Aamir MF, Ahmad M, Murtaza G, Khan SA. In vitro/in vivo assessment of flurbiprofen-matrix type transdermal delivery system. Lat. Am. J. Pharm. 2011; 30(2): 318-324.

2. Guy $R H$, Hadgraft J. Pharmacokinetics of percutaneous absorption with concurrent metabolism. Int. J. Pharm. 1984; 20: 43-52.

3. Chien YW, Banga K. Iontophoretic (transdermal) delivery of drugs: overview of historic development. $J$. Pharm. Sci. 1989; 78: 353-354.

4. Parasrampuria $D$, Parasrampuria J. Percutaneous delivery of proteins and peptides using iontophoric techniques. J. Clin. Pharm. Ther. 1991; 16: 7-17.

5. Stoughton RB. Percutaneous absorption. Toxicol. Appl. Pharmacol. 1967; 7: 1-8.

6. Shah SNH, Shahzad Y, Ansari MT, Haneef M, Malik M, Badshah A, Murtaza G. Permeation kinetic studies of physical mixtures of artemisinin in polyvinylpyrrolidone. Dissol. Technol. (Accepted for publication, 2012).

7. Shah SNH, Rabbani ME, Shahzad $Y$, Badshah A, Meidan YM, Murtaza G. Developing an efficacious diclofenac diethylamine transdermal formulation. J. Food Drug Anal. 2012; 20: 464-470.

8. Inayat $B P$, Setty $C M$. Chemical penetration enhancers for transdermal drug delivery systems, Trop. J. Pharm. Res. 2009; 8: 173-179.

9. Aamir MN, Ahmad M, Akhtar N, Murtaza G, Khan SA, Zaman SU, Nokhodchi A. Development and in vitroin vivo relationship of controlled-release microparticles loaded with tramadol hydrochloride. Int. J. Pharm. 2011; 407: 38-43.

10. Aamir MN, Ahmad M, Khan SA, Akhtar N, Murtaza G, Akhtar M, Rasool F. Fabrication of novel gastroretentive floating microcapsules by utilizing a combination of HPMC and EC and their physicochemical assessment. Lat. Am. J. Pharm. 2011; 30(5): 1010-1015.

11. Gupta GD, Gound RS. Release rate of nimesulide from different gellants. Indian J. Pharm. Sci. 1999; 61(4): 229-230.

12. Meidan VM, Pritchard D. A two-layer diffusive model for describing the variability of transdermal drug permeation. Eur. J. Pharm. Biopharm. 2010; 74(3): 513-517.

13. National Research Council. Guide for the care and use of laboratory animals. $8^{\text {th }}$ Edition. The National Academies Press, Washington DC, USA, 2011, pp. 1-23.

14. Soliman MS, Akram J, Hashem M, Mojgan RZ, Roshan $K$. The effect of some permeability enhancers on the percutaneous absorption of lidocaine. Pak. J. Pharm. Sci. 2010; 23: 83-88.

15. Trottet L, Merly C, Mirza M, Hadgraft J, Davis AF. Effect of finite doses of propylene glycol on the enhancement of in vitro percutaneous permeation of loperamide hydrochloride. Int. J. Pharm. 2004; 274: 213-219.

16. Yamane MA, Williams AC, Barry BW. Terpene penetration enhancers in PG/water co-solvent systems: effectiveness and mechanism of action. J. Pharm. Pharmacol. 1995; 47: 978-989.

17. Angela KL, Kaidi $Z$, Jagdesh $S$. Effect of ethanol/ propylene glycol on the in vitro percutaneous absorption of aspirin, biophysical changes and microscopic barrier properties of skin, Int. J. Pharm. 1999; 181: 255-263.

18. Jaehwi $L$, lan W. Combined effect of oleic acid and polyethylene glycol-200 on buccal permeation of encephalin from a cubic phase of glyceryl monooleate. Int. J. Pharm. 2000; 204: 137-144. 